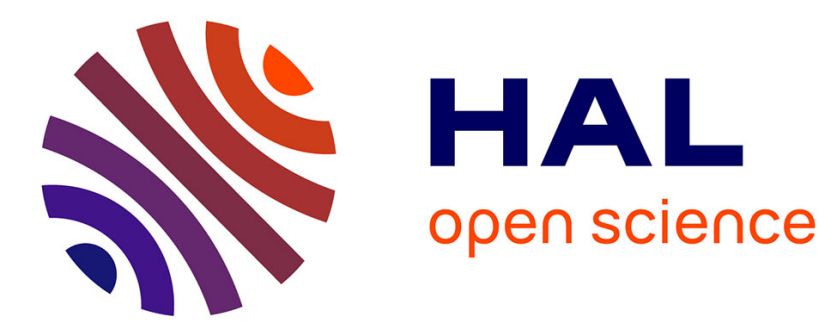

\title{
Promoting vernacular architecture, a basis for Building Back Safer? A Case study from Nepal
}

Eugénie Crété, Santosh Yadav, Yannick Sieffert, Majid Hajmirbaba, Julien

Hosta, Miguel Ferreira Mendes, Olivier Moles, Pawan Shrestha, Philippe

Garnier

\section{To cite this version:}

Eugénie Crété, Santosh Yadav, Yannick Sieffert, Majid Hajmirbaba, Julien Hosta, et al.. Promoting vernacular architecture, a basis for Building Back Safer? A Case study from Nepal. SAHC 2018, Sep 2018, Cusco, Peru. hal-01877189

\section{HAL Id: hal-01877189 \\ https://hal.science/hal-01877189}

Submitted on 19 Sep 2018

HAL is a multi-disciplinary open access archive for the deposit and dissemination of scientific research documents, whether they are published or not. The documents may come from teaching and research institutions in France or abroad, or from public or private research centers.
L'archive ouverte pluridisciplinaire HAL, est destinée au dépôt et à la diffusion de documents scientifiques de niveau recherche, publiés ou non, émanant des établissements d'enseignement et de recherche français ou étrangers, des laboratoires publics ou privés. 


\title{
Promoting vernacular architecture, a basis for Building Back Safer? A Case study from Nepal
}

\author{
Eugénie Crété ${ }^{1}$, Santosh Yadav², Yannick Sieffert ${ }^{3}$ Majid Hajmirbaba ${ }^{4}$, Julien Hosta ${ }^{5}$, Miguel Ferreira \\ Mendes $^{6}$, Olivier Moles ${ }^{7}$, Pawan Shrestha ${ }^{8}$ and Philippe Garnier ${ }^{9}$
}

\begin{abstract}
Reconstruction projects must rely on local resources and capacities to effectively reduce inhabitants' vulnerability on the long run. Vernacular architecture often reveals disaster-resilient strategies that are affordable and accessible to most people. Documenting and validating these practices through scientific research help in promoting them at different institutional and political levels. The work presented in this paper is a first step on the identification of the main factors affecting the incorporation of new practices in local building cultures and on the understanding of the extent to which these practices actually improve inhabitants' resilience. It results from a comparative study of two reconstruction projects in Nepal on the one hand and on the other hand from the research conducted by 3SR on a technique that is being reincorporated into inhabitants' building cultures: the regular insertion of seismic bands. The experimental campaign included tests on seismic bands built with different materials and cyclically loaded to assess the energy dissipated by the different configurations. The strong connection between academic and operational settings allowed for a direct contribution to the activities carried out by local stakeholders. Yet, the main factor affecting the people's acceptance of Building Back Safer (BBS) messages was the official guidelines they had to comply with to get subsidies; but it often resulted in important safety issues as their unaffordability induced improper implementations. Working on social aspects and side by side with local authorities is thus essential to widely implement proper BBS messages.
\end{abstract}

Keywords: vernacular architecture, aseismic design, seismic bands, Building Back Safer, Nepal

\footnotetext{
${ }^{1}$ Researcher, CRAterre laboratory, Architecture Environnement et Cultures Constructives Research Unit, Ecole Nationale d'Architecture de Grenoble, crete.e@grenoble.archi.fr

${ }^{2}$ Master student,Univ. Grenoble Alpes, CNRS, 3SR, F-38000 Grenoble, France, yadv.santos@ gmail.com

${ }^{3}$ Ass. Prof., Dr, Univ. Grenoble Alpes, CNRS, 3SR, F-38000 Grenoble, France, yannick.sieffert@3sr-grenoble.fr

${ }^{4}$ Engineer, CRAterre association, majid.hajmir@gmail.com

${ }^{5}$ Architect, CRAterre association, julien@ collectifcarpe.ch

${ }^{6}$ Architect, CRAterre association, m.ferreira.mendes@gmail.com

${ }^{7}$ Engineer, CRAterre association, olivier.moles@ @neuf.fr

${ }^{8}$ Architect, Head of ASF Nepal, ar.pawan@gmail.com

${ }^{9}$ Architect, Head of Habitat programme, CRAterre laboratory, Architecture Environnement et Cultures Constructives Research Unit, Ecole Nationale d'Architecture de Grenoble, craterre.pgarnier@ club-internet.fr
} 


\section{Introduction}

In disaster-prone areas, traditional architectures often reveal a great deal of ingenuity about the use of local resources and the development of techniques and practices that are thought to contribute to reducing the vulnerability of built structures [1], [2]. However, the relevance of these solutions remains marginally documented and validated by scientific communities. Hence, much damage is often inflicted on vernacular heritage through inappropriate retrofitting or repair and of course demolition during relief and reconstruction phases. The replacement of traditional habitat by 'modern' 'imported' solutions speeds up the disappearance of traditional skills, knowledge and cultural practices, putting living aspects of this heritage at risk [3]. Moreover, in many cases, it is ineffective in terms of Disaster Risk Reduction (DRR) [1] and it deprives inhabitants of solutions that are often the only one they can implement by themselves [4]. Identifying and analyzing what people actually do by themselves make it possible to improve it while perpetuating endogenous capacities for adaptation and evolution - which is decisive to improve inhabitants' resilience capacities in the long run - and while preserving their cultural identity [5].

The work presented is a first step on the identification of the main factors affecting the incorporation of new practices in people's building cultures and on the understanding of the extent to which these practices actually improve inhabitants' resilience. A strong collaboration between CRAterre-ENSAG, 3SR (UGA) and LMDC (INSA-Toulouse) makes it possible to study how structural engineering research influences these phenomena. This paper sums up the current findings that result from a comparative study of two reconstruction projects in Nepal and from the research conducted by 3SR on a technique that is being reincorporated into inhabitants' building cultures: the regular insertion of seismic bands. The research with LMDC is further developed in [6].

\section{Working methodology}

CRAterre-ENSAG and 3SR started collaborating through the research project ReparH, supported by the French National Research Agency (ANR) and launched following the 2010 earthquake in Haiti. This project supported the evolution of Haitian state policies regarding building standards [7] and resulted in two PhDs [2], [8] and on a methodology that was iteratively improved through a continuity of projects [9]. Its first step consists in the identification of local building practices and the elaboration of hypotheses regarding their relevancies towards DRR. The second step consists in selecting some of these practices according to their BBS potentials and the body of knowledge about them. The setup of a reverse engineering research protocol and its implementation by performing different tests and analyzing their results make it possible to extract intelligent building principles and define technical solutions that valorize and improve them, as and when needed. The strong interconnection with field projects allows for the construction of prototypes and the collection of direct feedbacks on the solutions promoted and their accuracy regarding local contexts. It thus allows for further adaptations of these practices and their full integration in the trainings implemented, and finally contributes to the definition of the research ways forward. 


\section{The identification of local DRR practices in Magapauwa and Katunje}

CRAterre-ENSAG and 3SR conducted two field surveys in November 2016 and February 2017 to analyze local building cultures and identify relevant DRR practices that would benefit from reverse engineering processes. They included buildings visits, interviews with inhabitants and professionals and group discussions. The first site selected is Magapauwa (Dolakha district), 3,000 inhabitants. The second one is Katunje (Dhading district), 1,500 inhabitants. Many buildings in these two sites were severely damaged during the 2015 earthquakes. The villages are located on steep hills and are difficult to access. Houses are built by hiring few local professionals, with a relevant participation of the owners on more specific tasks of the construction. A reconstruction project supported by Caritas Luxemburg started in these two sites in 2016. The Nepalese association Pourakhi is responsible for the overall project implementation with the technical support of Architectes Sans Frontières (ASF) - Nepal. CRAterre provides support to the project by reinforcing partners' capacities through technical and methodological advice.
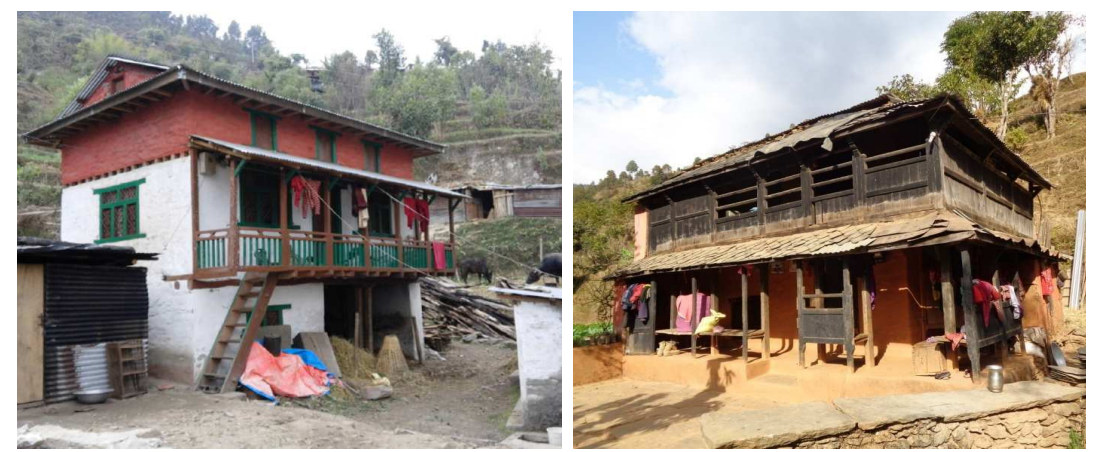

Figure 1. Traditional houses that resisted 2015 earthquakes with minor damage, in Magapauwa (left, credit: CRAterre) and Katunje (right, credit: ASF Nepal)

The load-bearing external walls are made of stone and mud mortar masonry and are 40 to $50 \mathrm{~cm}$ thick. Dressed stones are often used to reinforce corners. Internal partition walls are made of wood. Roofs are duo-pitched with an all-around eave. Traditional slates roofing are being replaced by Corrugated Galvanized Iron (CGI) sheets. This change started more than 20 years ago due to cost, ease of installation, and the inhabitants fearing heavy roofing in case of earthquakes. Several more specific traditional aseismic features were noticed:

- Doors and windows have a double timber frame which acts as an extra lintel when the masonry wall fails.

- Most of the remaining houses present wooden reinforcement at floor joists and awnings levels, and sometimes full timber seismic bands regularly spaced. In Katunje, several traditional buildings walls include stone bands spaced approx. $50 \mathrm{~cm}$.

- According to the connections between the awnings, they sometimes reduce the slenderness of the gable walls and confine the earthquake-sensitive upper part of the wall. However, this confinement is all the more efficient as the roof is heavy, which is becoming scarce with the replacement of slates by CGI.

- In Magapauwa, most houses are built with a double load-bearing system that is oversized for static loads, with masonry walls doubled by a post and beam timber structure. 
The observation of main post-earthquake failures (the delamination of masonry walls, corner collapses, failures at the connections between the walls and the roof framework, and partial collapse of gable walls) advocated for the improvement and the reincorporation of timber seismic bands in local building practices. But in both sites, the quality of the wood available is not fully satisfying for this purpose as the cutting of the traditionally used timber - shaal - is very restricted due to its increasing scarceness. It is then fundamental to reuse old timber, to develop wood protection techniques and to look for alternative materials or solutions.

\section{The seismic bands: academic research and recommendations}

Even if commonly found in historic buildings all over the world[10], seismic bands mechanical properties and influence on the seismic behaviour of buildings are still poorly known. But from observation, it is clear that a horizontal seismic band plays an important role in several manners. It prevents corner separations and reduces out-of-plane failures by restricting the bending deflection [11]. It helps to restrict in-plane shear crack propagations and acts as a temporary lintel in case of partial collapse of a wall. Moreover, it undergoes a sliding action which leads to dissipation of energy due to frictional behaviour at the interface layer.

The objectives of this experimental campaign are to find out the mechanical shear behaviour of different materials used to build shear bands and compare the energy they dissipate. A series of experimental tests was performed in cyclic quasi-static loading using the configurations and materials mentioned in the guidelines published by Nepalese government for reconstruction projects [12], [13].

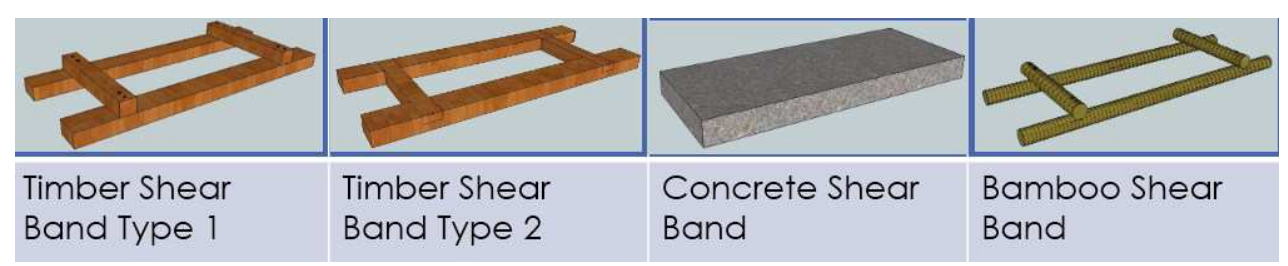

Figure 2. The different configurations of shear bands used for experimental work

For timber shear band type 1 and bamboo, the transverse ties were connected using nails; whereas for timber shear band type 2, the longitudinal pieces and the transverse member were embedded (see Figure 2). The dimension of longitudinal timber member is $900 \mathrm{~mm} \times 75 \mathrm{~mm} \times 45 \mathrm{~mm}$, and that of the transverse member is $350 \mathrm{~mm} \times 50 \mathrm{~mm} \times 45 \mathrm{~mm}$. For concrete shear bands, two main reinforcement bars with diameter $12 \mathrm{~mm}$ and stirrups having $6 \mathrm{~mm}$ diameter, spaced $150 \mathrm{~mm} \mathrm{C} / \mathrm{C}$ were used with $\mathrm{M} 20$ grade $(\mathrm{C}: \mathrm{S}: \mathrm{A}=1: 1.5: 3 \mathrm{ratio})$ concrete. Two identical specimens of each type are tested during the experiment.

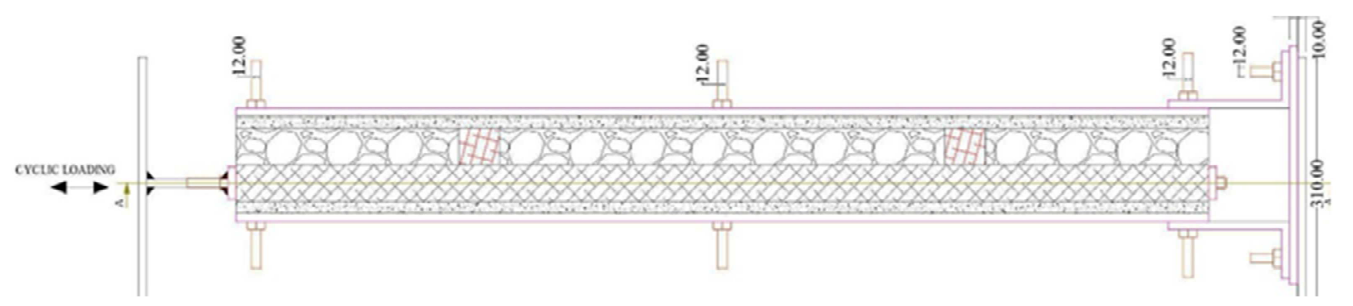

Figure 3. Longitudinal cross section of timber shear band type 1 during tests 
During the tests, the shear band is directly loaded to analyze the energy dissipation at the interface of the shear bands. The test is carried out in displacement controlled pattern with displacement up to $20 \mathrm{~mm}$ for three cycles at each level in both direction of loading [14]. The rate of displacement is $0.4 \mathrm{~mm} / \mathrm{sec}$ for each test. In order to take into account the pre-compressive load acting at the shear band level due to dead load of wall and live load from occupancy, a pre-compression is applied by confining with metallic plate connected by six bolts. Applied loads and displacements are recorded. Comparing the hysteresis curves for identical specimen (see Figure 4), the reproducibility requirement is addressed. To assess the amount of energy dissipated at each step, the area under the curve is calculated using OriginPro 2017 software. The comparison of energy dissipation by various types of shear bands is shown in Figure 5 .
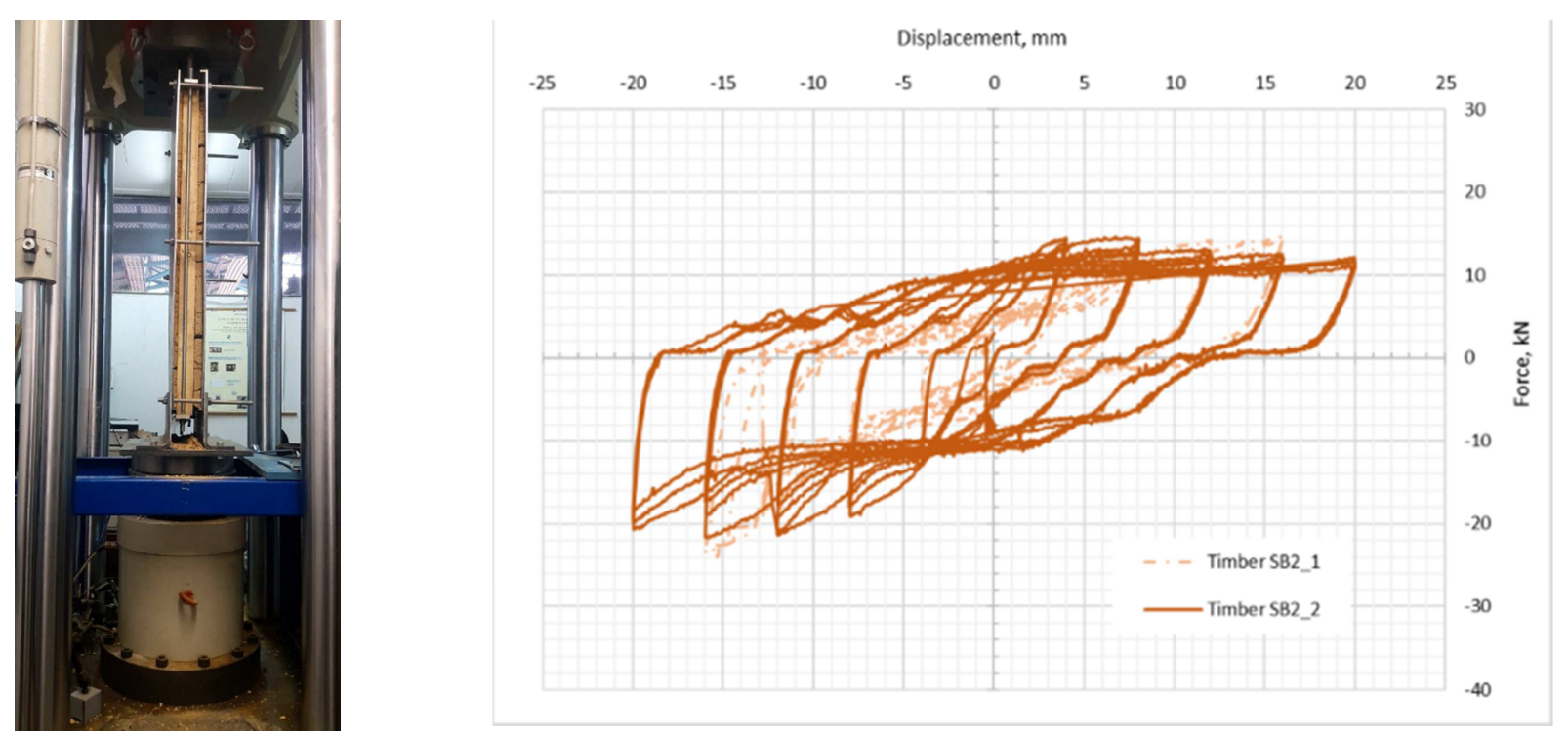

Figure 4. Experimental setup using Schenck machine (left) and hysteresis curves of the TSB2 under cyclic loading (right)

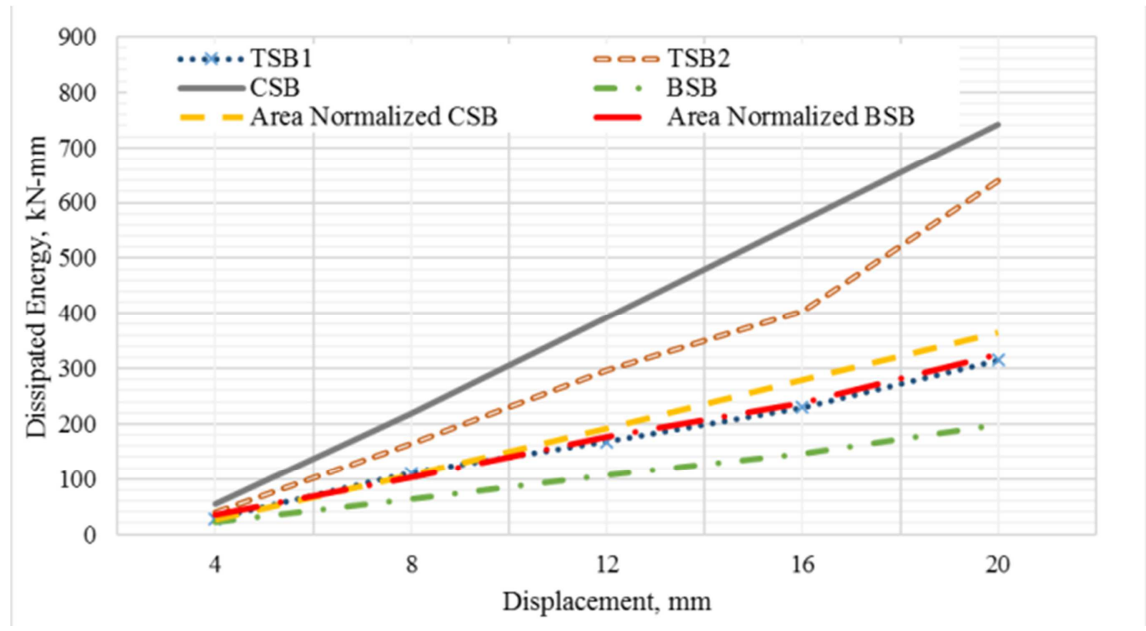

Figure 5. Comparison of energy dissipation by different types of shear bands

It shows that most energy is dissipated with concrete shear band (CSB) and least energy is dissipated with bamboo shear band (BSB). Moreover, it shows that the amount of energy dissipated is affected by the type of connection as Timber Shear Band type 2 (TSB2) dissipates more energy than Timber Shear Band type 1 (TSB1). Finally, to observe the significance of the shear band surface area, the results for the concrete and 
bamboo shear bands were normalized with respect to timber shear band area: the energy dissipated by the normalized CSB and normalized BSB are close to that of TSB1. The energy dissipation patterns tend to follow linear form for all different shear band configurations.

This first experimental work allowed us to conclude that:

- Timber shear band with notched transverse ties has better response property for shear loading and the energy dissipated is nearly twice as much as with nail connections. Moreover, type 2 is also probably performing much better regarding wall out-of-plane solicitation.

- The energy dissipation by the concrete shear band was highest among other materials because of its larger contact area.

- Bamboo shear band provides low energy dissipation as there is low friction and its contact area is small.

These conclusions on the energy dissipation should be put in perspective with the lack of knowledge on the other functions of the shear bands, and more specifically on the impact of their rigidity.

\section{The reincorporation of these results in the reconstruction projects}

As part of the reconstruction projects in Magapauwa and Katunje, ASF-Nepal and CRAterre provide technical support for all new constructions, retrofitting and repairing works in the villages. Moreover, two training sessions took place in November 2016 and May 2017. The demo houses that were constructed had three main functions: as a support for hands-on sessions during the training sessions, as a record of what trainees learned and as a showcase to share this knowledge with the other inhabitants.

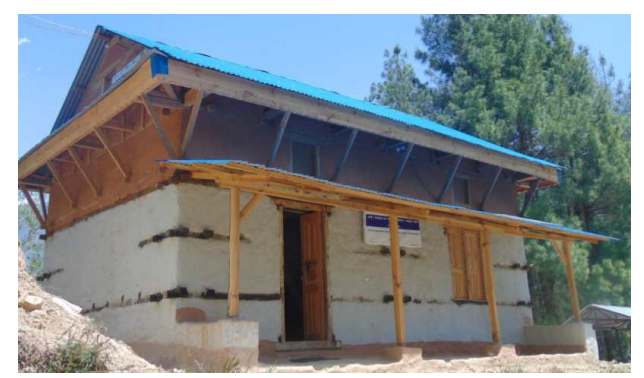

Figure 6. The demo house built in Magapauwa (credit: CRAterre)

During the training sessions, most of the traditional good practices that had been noticed were promoted [15]. A few changes in local ways of building were introduced to improve the safety and thermal properties of the constructions or to get closer to the specifications defined by the National Reconstruction Authority (NRA) to access the state subsidies [12], [13]. In particular, seismic bands were introduced and the height of the houses was reduced. The training was also the opportunity to improve the masons' know-hows as it was observed that most of them were no longer following the rules of art.

Moreover, some results from the experimental campaign carried out by 3SR on seismic bands directly fed the technical choices implemented during the training in Katunje:

- Though concrete seismic band seems efficient regarding the energy dissipation, its cost is usually much higher than that of timber and local workers often lack basic skills to build it. 
- Low quality nails do not allow for satisfying connections when using hard timber and the research further argued for the use of embedded connections.

However, the field surveys showed that complying with the technical guidelines issued by the NRA was of high importance to people when they had to choose for the materials and techniques they would use, and the first set of NRA requirements, issued in 2015 [12] did not include the use of timber seismic bands to build houses with more than one level. In Magapauwa, 36 houses were rebuilt or under reconstruction by July 2017. They were built in stone masonry with mud mortar, with a better quality regarding stone works. All but three households preferred building two-level houses with Reinforced Cement Concrete (RCC) seismic bands, as allowed by the official guidelines. But as it was too expensive, they saved money by hiring unskilled workers and reducing the amount of iron rods and cement, thus inducing important safety issues. It was complex to convince inhabitants and professionals about the importance of building RCC seismic bands in compliance with technical guidelines and explain why using timber was safer than using RCC improperly. In Katunje, in July 2017, one mason had built his own house following the guidelines co-developed by CRAterre and ASF and reusing timber and stones from his previous house. This new building is complying with most guidelines and is satisfactory regarding safety and earthquake engineering. Otherwise, most people were still living in their damaged houses: Even when reusing most materials - which is quite easy for most households - people still have to spend around NPR 300,000 for labor, which represents the total grant given by the government for reconstruction. But this grant is given in three instalments and most people received only half of it (as the last instalment is to be paid when the works are over).

\section{Conclusions}

It seems that the main factor affecting the implementation of DRR messages was the official guidelines people had to comply with to get subsidies. They resulted in an improvement of masons' skills regarding stone masonry, but the improper implementation of RCC seismic bands induced much safety issues. The NRA asked for more scientific knowledge on timber bands before fully integrating this technique in their guidelines. The research conducted by 3SR and CRAterre-ENSAG partly aimed at answering their concern. The NRA finally allowed for two-story constructions with timber seismic bands in their second set of guidelines, published in 2017 [13]. Analyzing how this decision influenced the reconstruction processes in Magapauwa and Katunje will be of high interest. Working with local authorities is essential to widely convey proper DRR messages.

Besides, the project teams are to socially assist the most vulnerable inhabitants by tailoring solutions enabling them to access materials and labor, for example by revitalizing traditional work exchange systems. This turned successful in Haiti, but was not enforced yet in Nepal, resulting in a low accessibility of all kind of houses.

Finally, seismic bands behave very differently depending on their rigidity and the building one, and further research is necessary to understand their behaviour.Moreover, in order to allow for a dissipative movement and increase the friction when using bamboo, local engineers decided to improve the roughness of the bamboo and 
increase its contact area by testing crushed and tangled bamboo bands, and to test the feasibility of this technique when building the next outbuildings. The current development of an affordable shaking table at 3SR will allow for testing real-scale technical details and conducting more academic research, included through partnership with local universities.

\section{Acknowledgments}

The authors would like to thank the University of Grenoble Alpes for its support with the AGIR-PEPS 2016 programme (Alpes Grenoble Innovation Recherche Programme Exploratoire Premier Soutien).

This work has been realised in the framework of the LABEX AE\&CC as part of the program "Investissements d'Avenir" overseen by the French National Research Agency (reference: ANR-10-LABX-0083) and located at ENSAG (High school of architecture of Grenoble).

\section{References}

[1] Ferrigni F, Centro universitario europeo per i beni culturali di Ravello (2005) Ancient buildings and earthquakes: reducing the vulnerability of historical built- up environment by recovering the local seismic culture : principles, methods, potentialities. Bari: Edipuglia.

[2] Caimi A (2014) Cultures constructives vernaculaires et résilience : entre savoir, pratique et technique : appréhender le vernaculaire en tant que génie du lieu et génie parasinistre. PhD thesis. Grenoble: University of Grenoble.

[3] Jigyasu R (2002) Reducing disaster vulnerability through local knowledge and capacity: the case of earthquake prone rural communities in India and Nepal. PhD thesis. Trondheim: Norwegian University of Science and Technology (NTNU).

[4] CRAterre (2010) Manifeste «Valoriser les cultures constructives locales pour une meilleure réponse des programmes d'habitat ».

[5] Garnier P, Moles O, Caimi A, Gandreau D, Hofmann M (2013) Natural hazards, disasters and local development. Villefontaine: CRAterre.

[6] Vieux-Champagne F, Aranguren J, Laffineur M, Aubert J-E (2018) Experimental analysis of timber inclusions effect on paraseismic behavior of earth masonry walls, 11th International Conference on Structural Analysis of Historical Constructions.

[7] Joffroy T, Garnier P, Douline A, Moles O (2017), Rebuilding Haiti. Grenoble: CRAterre.

[8] Vieux-Champagne F (2013) Analyse de la vulnérabilité sismique des structures à ossature en bois avec remplissage : essais expérimentaux - modélisation numérique - calculs parasismiques. $\mathrm{PhD}$ thesis. Grenoble: University of Grenoble.

[9] Caimi A (2010) Assessing local building cultures for resilience and development. Villefontaine: CRAterre.

[10] Hofmann M (2015) Le facteur séisme dans l'architecture vernaculaire. Un décryptage entre déterminants culturels, types de structures et ressources cognitives parasismiques. PhD thesis. Lausanne: EPFL.

[11] Arya AS, Boen T, Ishiyama Y (2014) Guidelines for earthquake resistant non-engineered construction. Paris: UNESCO.

[12] Nepal Housing Reconstruction Programme (2015) Design catalogue for reconstruction of earthquake resistant houses - Volume 1.

[13] Nepal Housing Reconstruction Programme (2017) Design catalogue for reconstruction of earthquake resistant houses - Volume 2.

[14] Vieux-Champagne F, Sieffert Y, Grange S, Polastri A, Ceccotti A, Daudeville L (2014) Experimental analysis of seismic resistance of timber-framed structures with stones and earth infill, Eng. Struct., vol. 69, p. 102-115.

[15]Ferreira Mendes M, Hosta J, Le Gall O (2015) Technical guide for master trainers: earthquake resistant buildings using local materials in Dolakha, Ramechhap and Sindhuli - Nepal. 